\title{
A Comparative Analysis of Two Full-Scale MD-500 Helicopter Crash Tests
}

\author{
Justin Littell \\ ATK Space Systems, NASA Langley Research Center MS 495, 12 W. Bush Rd, Hampton Virginia 23681 \\ Justin.D.Littell@nasa.gov
}

\begin{abstract}
Two full scale crash tests were conducted on a small MD-500 helicopter at NASA Langley Research Center's Landing and Impact Research Facility. One of the objectives of this test series was to compare airframe impact response and occupant injury data between a test which outfitted the airframe with an external composite passive energy absorbing honeycomb and a test which had no energy absorbing features. In both tests, the nominal impact velocity conditions were $7.92 \mathrm{~m} / \mathrm{sec}$ $(26 \mathrm{ft} / \mathrm{sec}$ ) vertical and $12.2 \mathrm{~m} / \mathrm{sec}(40 \mathrm{ft} / \mathrm{sec}$ ) horizontal, and the test article weighed approximately $1315 \mathrm{~kg}(2900 \mathrm{lbs})$. Airframe instrumentation included accelerometers and strain gages. Four Anthropomorphic Test Devices were also onboard; three of which were standard Hybrid II and III, while the fourth was a specialized torso. The test which contained the energy absorbing honeycomb showed vertical impact acceleration loads of approximately $15 \mathrm{~g}$, low risk for occupant injury probability, and minimal airframe damage. These results were contrasted with the test conducted without the energy absorbing honeycomb. The test results showed airframe accelerations of approximately $40 \mathrm{~g}$ in the vertical direction, high risk for injury probability in the occupants, and substantial airframe damage.
\end{abstract}

\section{Introduction}

The Landing and Impact Research Facility (LandIR) at NASA Langley Research Center (LaRC) has a long history of aircraft and

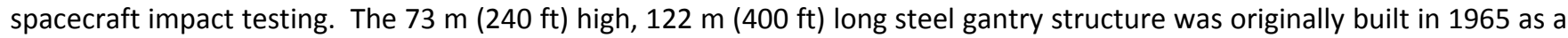
training facility for astronauts to practice landing on the moon during the Apollo program [1]. It has since been converted for use as a full-scale aircraft crash test facility [2]. Since the mid 1970s, over 150 vehicles comprising a mix of general aviation aircraft, helicopters, and fuselage subsections have been tested at LandIR [3]. Currently, the facility supports NASA's Constellation and Subsonic Rotary Wing Crashworthiness research programs for Orion crew module landing and rotorcraft impact testing. The LandIR is shown in Figure 1.

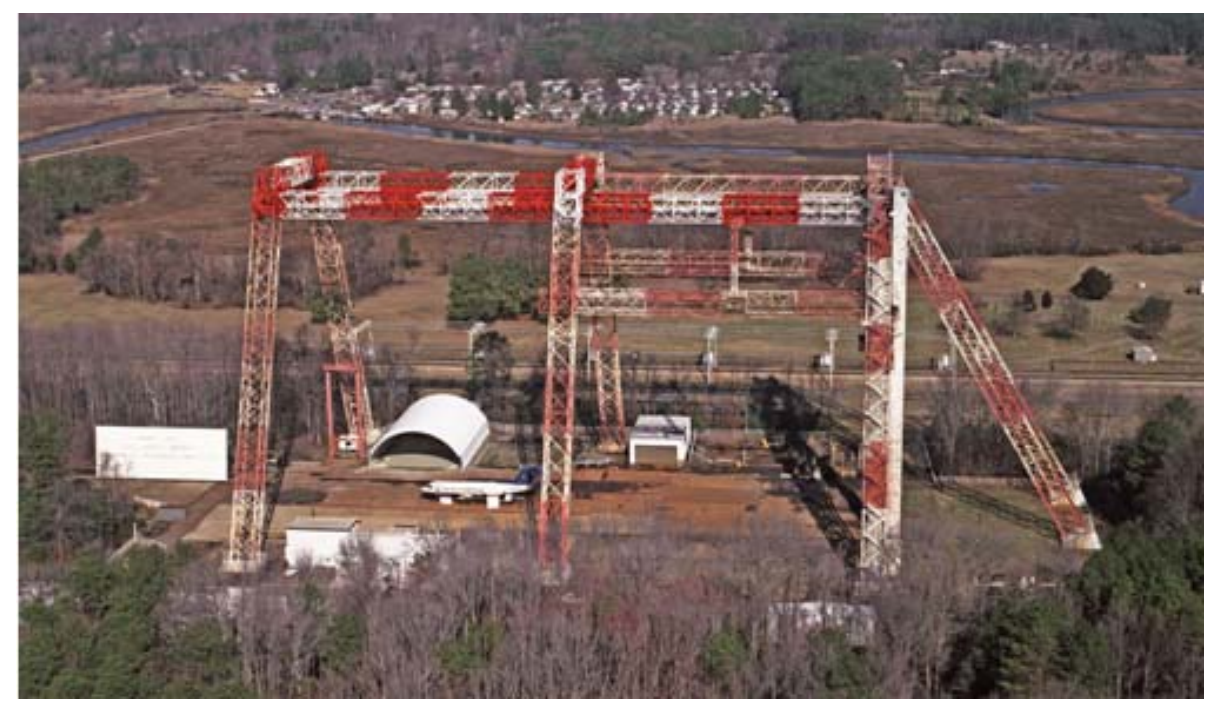

Fig. 1 LandIR Facility at NASA LaRC 
Research in aircraft crashworthiness has mainly been focused on the attenuation of impact loads and ultimately the mitigation of crew or occupant injury. External airframe airbags are a common external energy absorbing concept, which have been evaluated for crash attenuation [4-5] in the past. Similar to an automotive airbag system, these deploy immediately before impact and offer attenuation through active or passive venting systems. One design challenge with airbags is the high shear forces seen from horizontal velocities, which can make them unstable and unreliable during impacts involving high forward velocities.

At NASA LaRC, a program has been implemented to demonstrate a novel Deployable Energy Absorbing (DEA) composite honeycomb concept [6-8] as an alternative to the conventional airbag system. Originally developed for evaluation on NASA's Orion spacecraft, the DEA was also considered for aircraft as a potential device to attenuate crash loads transmitted to crew members and to alleviate occupant injuries. The DEA structure was fabricated from Kevlar/epoxy composite sheets and then assembled to form hexagonal cell walls. The DEA featured a flexible hinge design at the junctions of each individual hexagonal cell which allows the entire structure to lay flat until deployment. A mechanism deploys the DEA such that the cells open and form their honeycomb shape oriented normal to the airframe and impact surface. Figure 2 shows a sample DEA test article used in a subscale crush test so that the reader can familiarize themselves with the concept. Note these photos do not depict the actual DEA used in the full scale test.
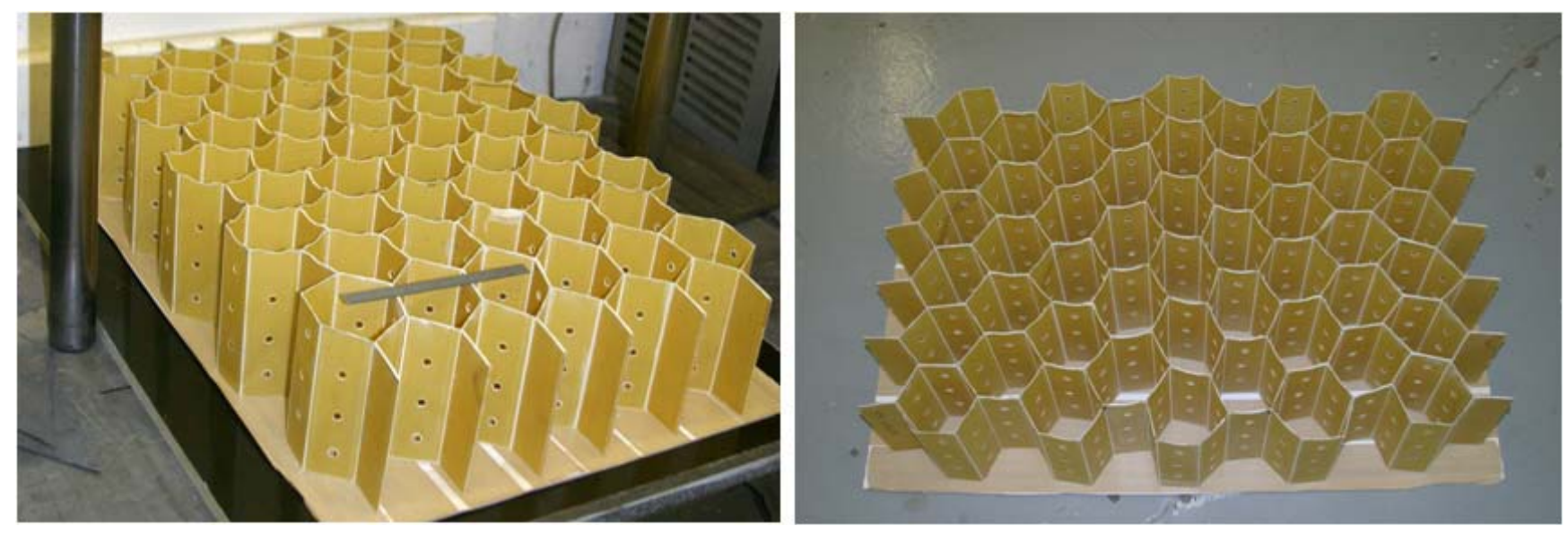

Fig. 2 An example DEA used in subscale testing. Isometric view (left) and top view (right)

As a demonstration of concept, engineers at NASA LaRC conducted two tests on a small MD-500 helicopter which enabled an evaluation of the DEA concept on an actual airframe under realistic crash conditions. In the two full-scale impact tests conducted, the first test included the DEA structure externally attached to the airframe while the second was a baseline test that did not include the DEA structure. Identical initial conditions, with the exception of the presence of the DEA, were present for both tests such that the performance of the DEA could be evaluated using metrics including airframe accelerations and loads, human occupant injury thresholds and limits, and airframe deformation.

\section{Test Article Description}

The MD-500 is a derivative of the Hughes OH-6 helicopter and over 5,000 airframes have been built since 1982 . The latest civilian utility variant is the MD-500E. The military derivative of the helicopter is the Defender series that is currently in service in the US Army. Currently, the MD-500E is used as a general-purpose utility and executive transport helicopter. Maximum gross weight is $1,360 \mathrm{~kg}(3,000 \mathrm{lb})$, with an empty weight of $703 \mathrm{~kg}(1,550 \mathrm{lb})$. The total length of the airframe is $9.4 \mathrm{~m}(30.84 \mathrm{ft})$ and the tail height is $2.7 \mathrm{~m}(8.9 \mathrm{ft})$. The as-received test article weighed approximately $227 \mathrm{~kg}(500 \mathrm{lb})$, and is shown in Figure 3. Components not included in the as-delivered helicopter were the engine and gear box, main rotor, rear tail and tail rotor, avionics, fuel tanks, seats, restraints and doors. 

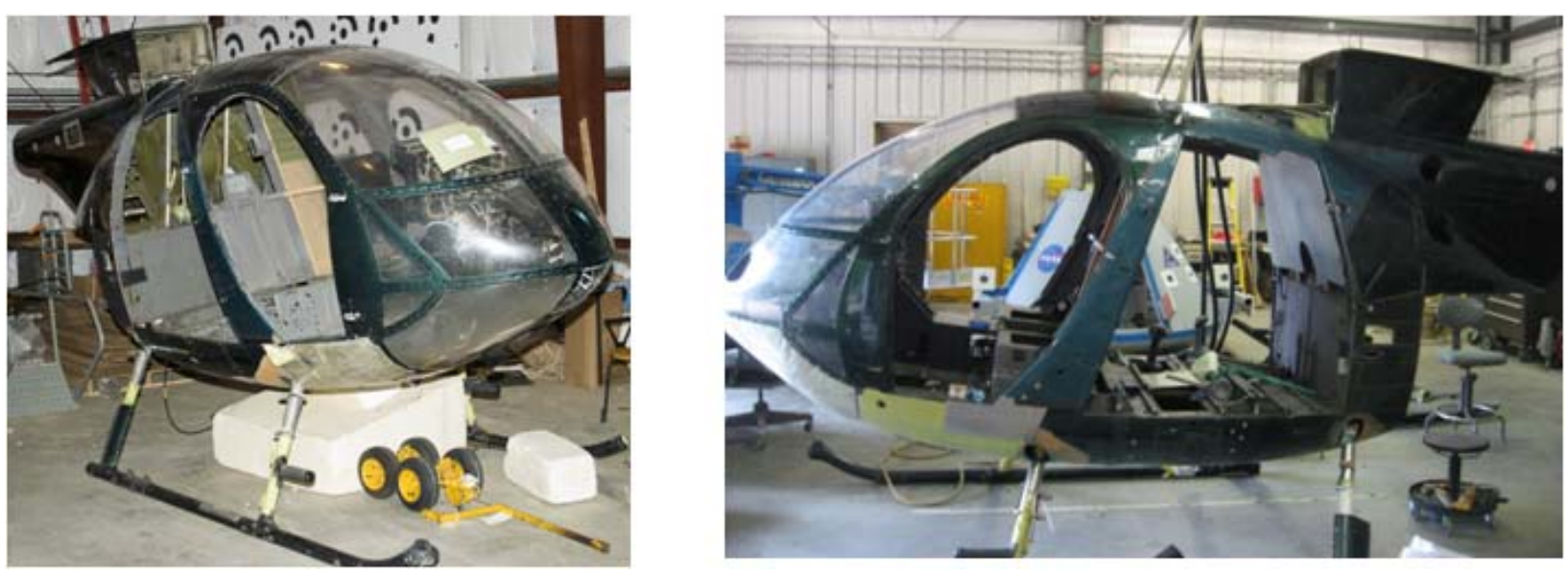

Fig. 3 As-Received MD-500 Helicopter Test Article

Modifications were necessary to prepare the MD-500 helicopter for the tests. Major modifications included:

1 - Damaged aluminum skin near helicopter tie down points and acrylic windshield panels were replaced or repaired.

2 - Original oleo-pneumatic skid gear struts were replaced with crushable energy absorbing struts. [9]

3 - The test which included the DEA only: Four layers of $0.25 \mathrm{~mm}(0.010 \mathrm{in})$ thick graphic/epoxy fabric were added to the belly to enhance the load carrying capability due to the expected loading from the DEA crushing.

4 -Aluminum straps were added to each side of the helicopter at the exterior water line level to serve as DEA tie down attachment points.

5 - Box beams were added to the front and rear bulkheads to serve as LandIR cabling system attachment points.

6 - Ballast mass, in the form of lead blocks, was placed in locations representing major structural and mechanical components of the aircraft, such as the engine and transmission, main rotor, tail rotor, doors, and instrument panel.

7 - Sand bags were placed in the rear sub-floor to represent fuel ballast.

8 - Original skid gear was replaced with new gear. New skid gear was installed for each test.

9 - New front bucket and rear bench seats were installed for each test.

The airframe was tested in the modified configuration for both tests, even though only a small number of the modifications were directly involved with the DEA and DEA attachment hardware. For example, the aluminum straps added to the water line of the airframe for the DEA attachment tie-down locations were left on the airframe for the test without the DEA to generate comparable test data. The test weight for the MD-500 with DEA test was $1329 \mathrm{~kg}(2930 \mathrm{lb})$, while the test weight for the MD-500 without DEA test was $1318 \mathrm{~kg}(2906 \mathrm{lb})$. The $9 \mathrm{~kg}(24 \mathrm{lb})$ difference was due to the removal of the DEA between tests. The weight and center of gravity (CG) of the airframe stayed within realistic limits. [10]

The helicopter was instrumented with 160 channels of instrumentation to collect strain, acceleration, load and Anthropomorphic Test Device (ATD) occupant response data. Accelerometers were placed on critical components of the airframe, ballast locations, floors and subfloors, while strain gages were placed on the bulkheads, keel beam, and skid gear. Four ATD occupants were onboard the helicopter for both tests. The pilot (front left) was a Hybrid III $50^{\text {th }}$ percentile ATD. However, instead of the standardized curved spinal column, the spinal column was replaced with an FAA approved straight spinal column [11]. The co-pilot (front right) and rear passenger (rear right) were a standard Hybrid II $50^{\text {th }}$ percentile ATD, which normally includes a straight lumbar spinal column. The left rear was a specialized human surrogate torso model (HSTM), designed to measure the internal loads on a human torso [12]. The HSTM torso was attached to a standard Hybrid III pelvis and lower extremities. The front pilot and co-pilot were seated in mesh cloth bucket seats. The rear occupants sat on a mesh bench seat. Figure 4 shows the pre impact configuration of the helicopter before each test. 

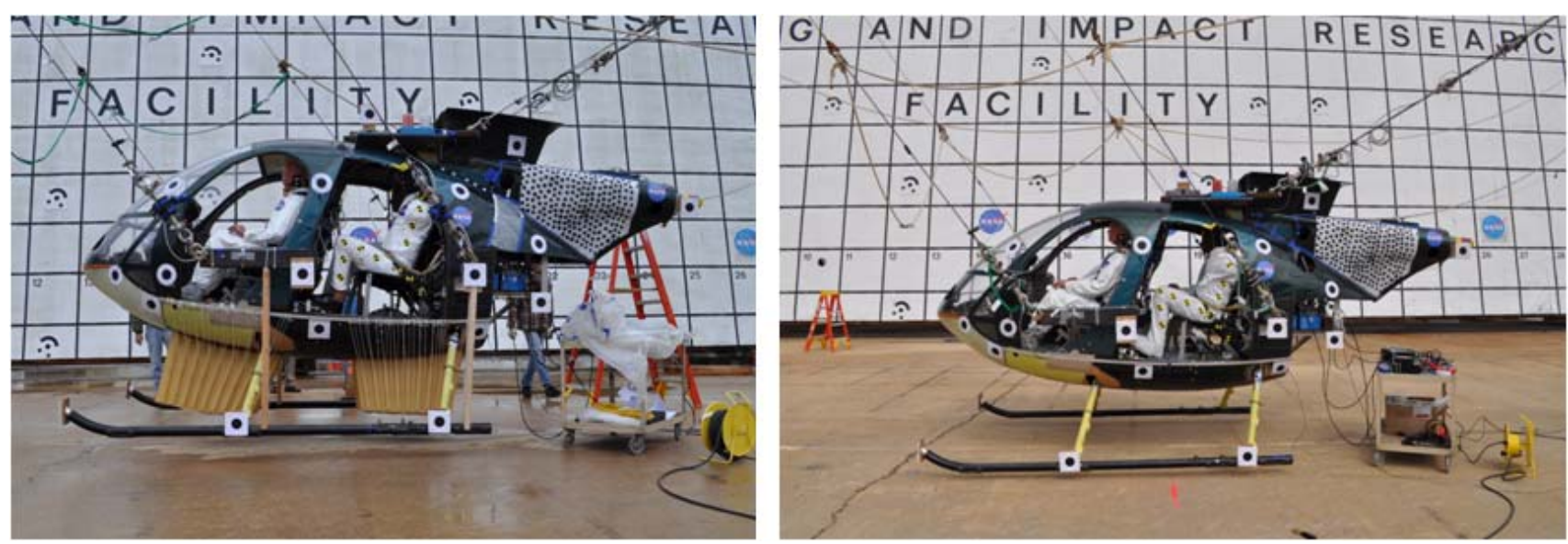

Fig. 4 Pre test configurations of the MD-500 helicopter: DEA configuration (left); baseline configuration (right)

The aircraft was also covered with black and white targets for use in a photogrammetric imaging system. These targets were $7.6 \mathrm{~cm}$ ( $3 \mathrm{in}$ ) diameter black dots mounted on specific locations on the airframe to determine impact velocities and orientations, and post-impact structural integrity of the airframe. The numbering scheme of the targets for the test which included the DEA is shown in Figure 5. Note that the target numbering scheme was identical for both tests.
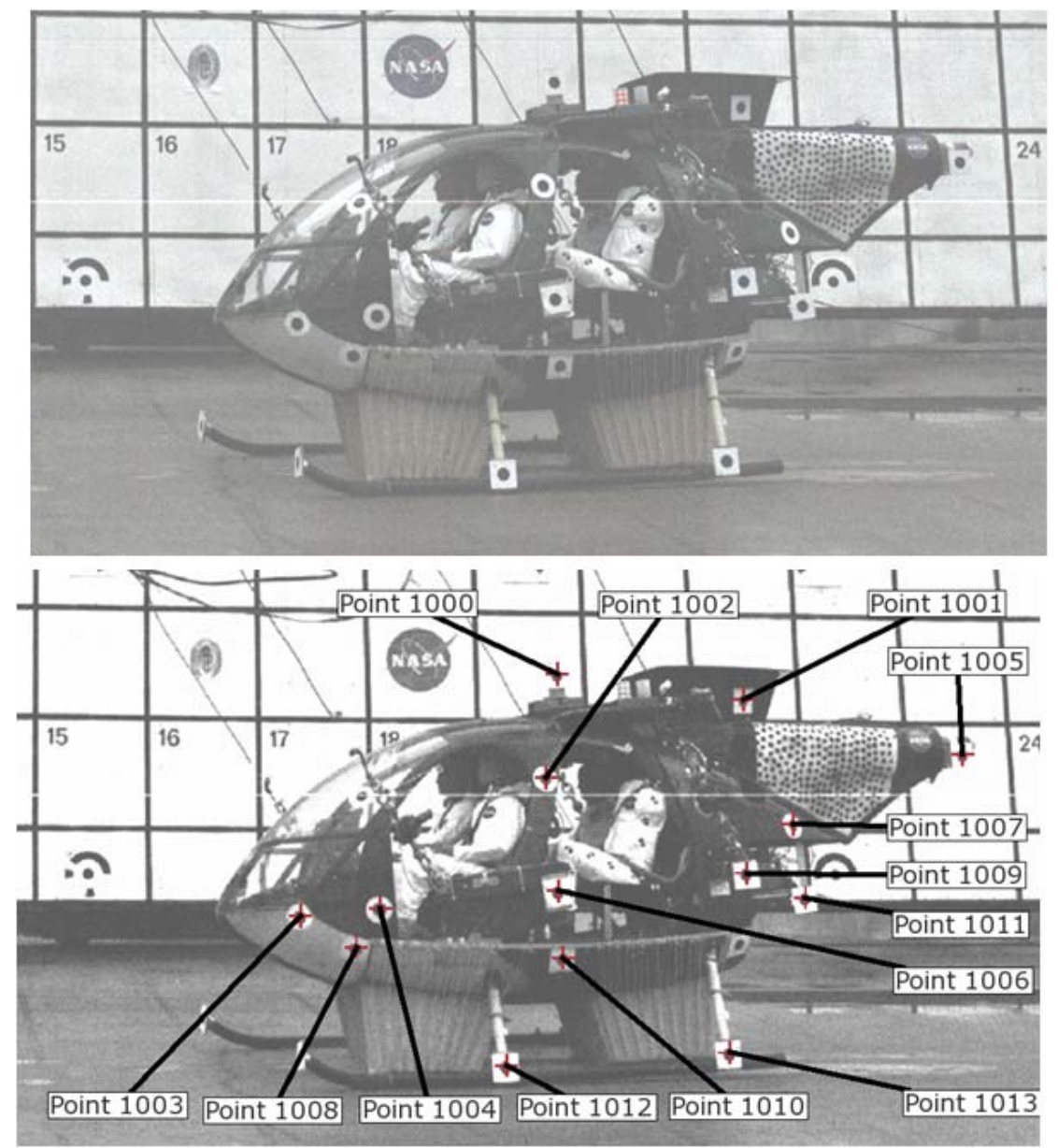

Fig. 5 Frame of video from MD-500 with DEA test (top) and identified target locations (bottom) 
The nominal impact conditions for the full-scale crash tests were $12.19 \mathrm{~m} / \mathrm{s}$ (40 fps) horizontal and $7.92 \mathrm{~m} / \mathrm{s}(26 \mathrm{ft} / \mathrm{sec})$ vertical velocities giving a resultant velocity of $14.54 \mathrm{~m} / \mathrm{s}(47.7 \mathrm{fps})$ at a 33 degree glide angle for both tests. The impact surface was concrete. The particular velocities were chosen to represent a severe, but survivable crash, and not explicitly based on any particular crashworthiness standard such as MIL-STD-1290A [13]. The impact conditions were achieved by swinging the helicopter through a pendulum style fashion using LandIR cabling equipment and hardware. This was achieved through two sets of parallel swing cables, located on either side of the vehicle, and a pullback cable. The pullback cable lifted the vehicle to the specified drop height and was then pyrotechnically cut at the beginning of the test, allowing the vehicle to swing toward the ground via the swing cables. Immediately before impact, pyrotechnics severed the swing cables such that free fall impact conditions were present immediately prior to impact. Figure 5, above, shows the helicopter immediately after the swing cables have separated.

\section{Results}

The measured impact conditions were determined through photogrammetric techniques by tracking the rigid body motion of the vehicle through the final portion of the swing. All tracked points were averaged to achieve a final impact velocity. For angle and angular rate measurements, the photogrammetric software tracked projected angles between the vehicle and the stationary photogrammetric backboard. For a complete description of photogrammetric techniques used, see reference 14. Table 1 lists the velocity, attitude, and angular rates recorded from each test.

The three translation velocities between tests match well and are only slightly different from the nominal $12.2 \mathrm{~m} / \mathrm{s}$ (40 $\mathrm{ft} / \mathrm{sec}$ ) forward, $7.9 \mathrm{~m} / \mathrm{s}(26 \mathrm{ft} / \mathrm{sec})$ vertical and $0 \mathrm{~m} / \mathrm{s}(0 \mathrm{ft} / \mathrm{sec})$ lateral velocity conditions. The lower-than-anticipated forward and vertical velocities can be attributed to air resistance and friction in the cabling systems, while the non-zero lateral velocity can be attributed to prevailing wind conditions pushing the test article off center. The pitch down attitude present in both tests was attributed to the CG of the vehicle being slightly forward of the midpoint for the LandIR parallel swing cabling system. There was a higher-than-normal amount of roll and yaw present for the test which included the DEA. These high values were attributed to misalignment of the LandIR cabling pullback harness. This issue was only identified during post-test data analysis. The harness was modified for the baseline test, and both the roll and yaw conditions were much closer to nominal at approximately 2 degrees. The pitch rate stayed approximately the same between tests, which was assumed to be constant since the longitudinal location of the CG did not change. The yaw rate was especially high for the test which included the DEA as the uneven pullback harness created cable preload misalignments. The change in pullback harness also corrected the rate results for the baseline test.

Table 1 - Impact Conditions

\begin{tabular}{|c|c|c|}
\hline Impact Parameter & $\begin{array}{c}\text { MD-500 with } \\
\text { DEA }\end{array}$ & $\begin{array}{c}\text { MD-500 without } \\
\text { DEA }\end{array}$ \\
\hline Linear velocity $-\mathrm{m} / \mathrm{s}(\mathrm{ft} / \mathrm{sec})$ & & \\
\hline Forward & $11.8(38.8)$ & $11.9(39.1)$ \\
\hline Vertical & $7.8(25.6)$ & $7.3(24.1)$ \\
\hline Lateral & $0.2(0.5)$ & $0.2(0.6)$ \\
\hline Resultant & $14.2(46.5)$ & $14.0(45.9)$ \\
\hline Attitude (deg) & & \\
\hline Pitch & -5.69 & -6.2 \\
\hline Roll & 7.04 & 1.9 \\
\hline Yaw & 9.3 & 2.1 \\
\hline Angular Velocity $($ deg/sec) & & \\
\hline Pitch Rate & 0.44 & 0.54 \\
\hline Roll Rate & 1.11 & 0.68 \\
\hline Yaw Rate & 4.82 & 1.65 \\
\hline
\end{tabular}


Figures 6 and 7 show still-frame side views from the high speed camera for each test. The figures depict four images each. These four images represent the MD-500 helicopter before impact, at first ground contact, at maximum vertical deflection, and during post-impact rebound. Figure 6 shows a picture of the MD-500 test which included the DEA, while Figure 7 shows a picture of the baseline test.

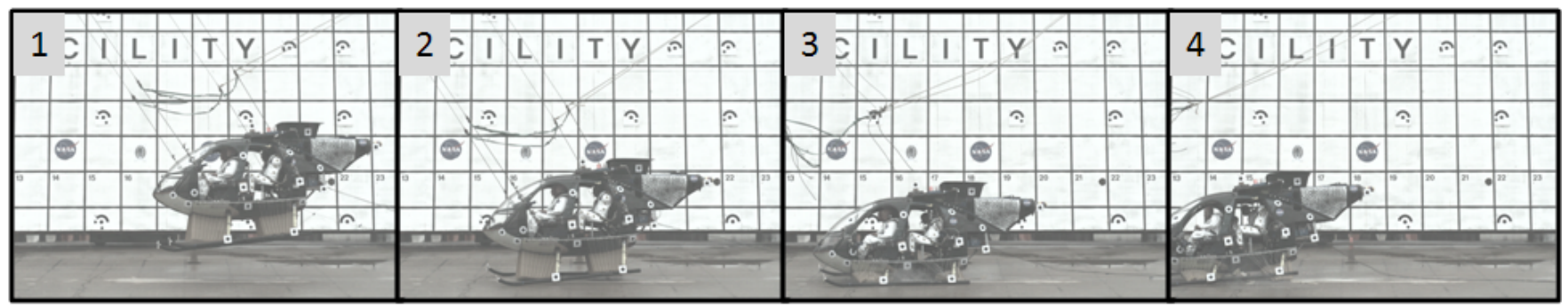

Fig. 6 MD-500 test which included the DEA - Image Sequence

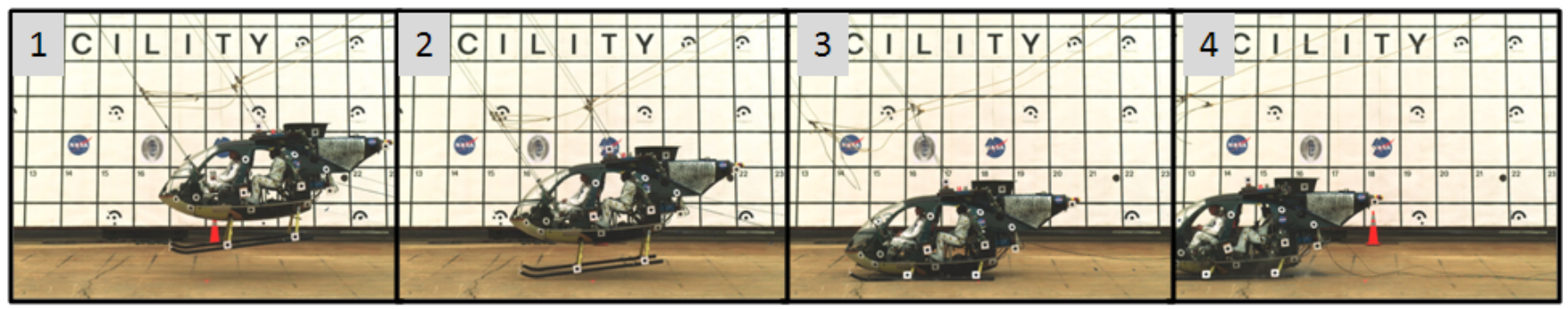

Fig. 7 MD-500 baseline test - Image Sequence

In Figure 6, picture 1 (left) shows the helicopter approximately $30 \mathrm{~ms}$ before impact, pitched down and with some slight yaw. The yaw can be seen by noting the difference in horizontal position in the near and far skid gear. Picture 2 (left center) shows the helicopter at the point of right skid gear impact. Picture 3 (right center) shows the point of maximum DEA crushing stroke, and picture 4 (right) shows a post-impact rebound, again noting that the vehicle's nose has pitched down. At the point of maximum crush deflection (picture 3), the helicopter straightened out to show almost no pitch. After the point of maximum crush, the nose pitched forward on the rebound, presumably due to friction between the DEA and the impact surface. An analogous sequence is shown in Figure 7 for the MD-500 test which did not include the DEA.

In Figure 7, picture 1 (left) shows the helicopter before impact. Note that due to the minimal roll and yaw present, the tips of the near and far skid gears were approximately at the same longitudinal position. Picture 2 (left center) shows the helicopter at the point of first skid gear impact. As before, for the MD-500 baseline test, the far (right) gear impacted the ground first which was due to the minor amount of yaw and roll present. Picture 3 (right center) shows the point of maximum vertical displacement, noting that the helicopter still had a down pitch orientation. Picture 4 (right) shows a post-impact rebound. After the point of maximum vertical deflection, the nose pitched forward on the rebound, presumably due to the downward pitch of the nose at impact. Post test photographs document some of the differences in the helicopter after the completion of each test, and are included to show the damage incurred. Figure 8 shows the post impact position of the helicopter immediately after each test.

Due to the presence of some yaw in both tests, the helicopter turned to the left during the post-impact slide out. The slide

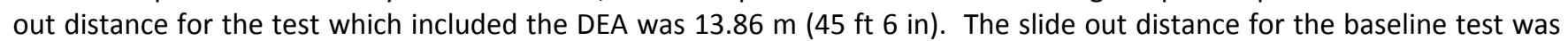
$15.57 \mathrm{~m}(51 \mathrm{ft} 1 \mathrm{in})$. The slide out difference is attributed to the friction contact between the DEA and the impact surface. The MD-500 with DEA turned a greater distance, presumably due to the greater amount of yaw and yaw rate. Finally, it is noted that all of the onboard occupants for both tests are leaning to their right, presumably from the helicopter turning to the left. 
Further inspections were completed after the helicopter was moved from the impact area. Figure 9 shows the condition of the front bucket and rear bench seats after the baseline test. Pictures of the test which included the DEA are not shown because the seats remained intact during that test. However, Figure 9 shows the front bucket seats buckled in multiple places, one of which is highlighted in Figure 9(a), while much of the rear seat failed, as shown in Figure 9(b). The rear support beam sheared from its connection points, while the front beam and the side beams have sheared and split at their attachment point junctions.

The seats and occupants were removed from the airframe and deformations of the supporting seat box structure were examined. Figure 10 shows the structure in the vicinity of the front seat box for the MD-500 baseline test. The post test photographs show extensive damage around the seat box area for the baseline test. The buckling of the front bucket seats caused the occupants to directly impact and dent the seat box cover. The seat box was cracked and the seat box support structure buckled. Figure 11 shows pictures looking further down below the seat box and into the subfloor.
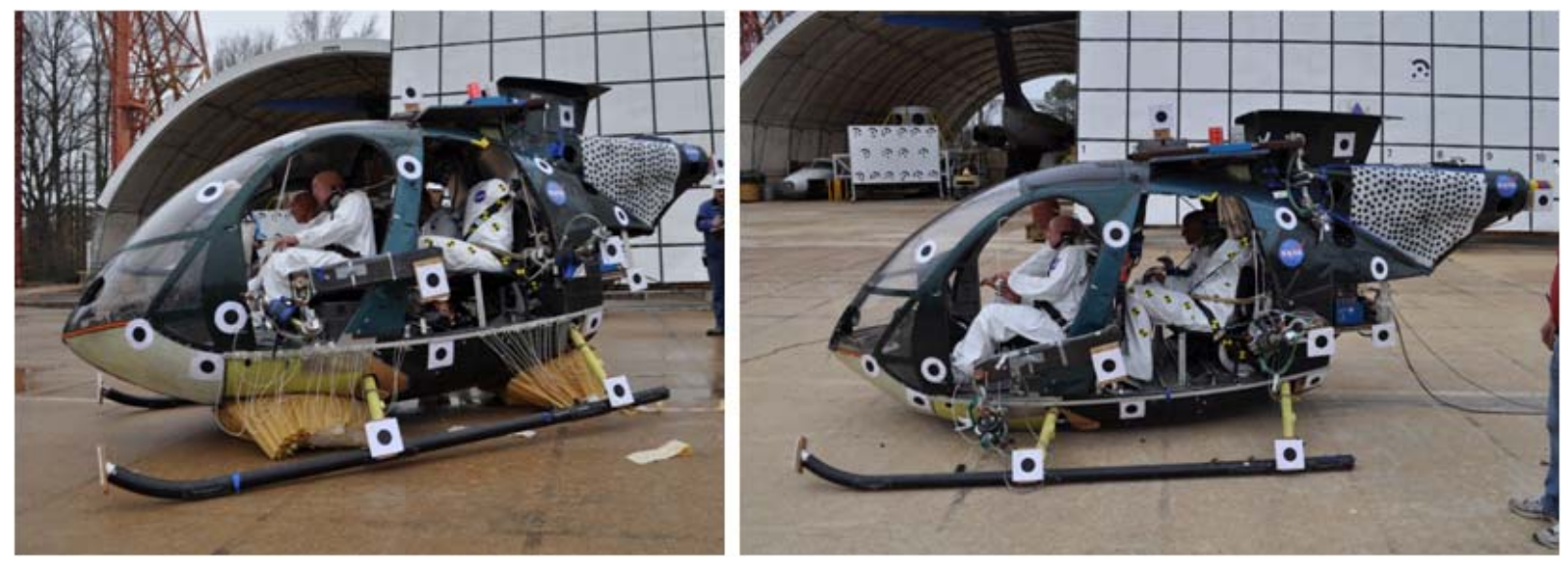

Fig. 8 Post test impact position of the MD-500 with DEA (left) and baseline (right)

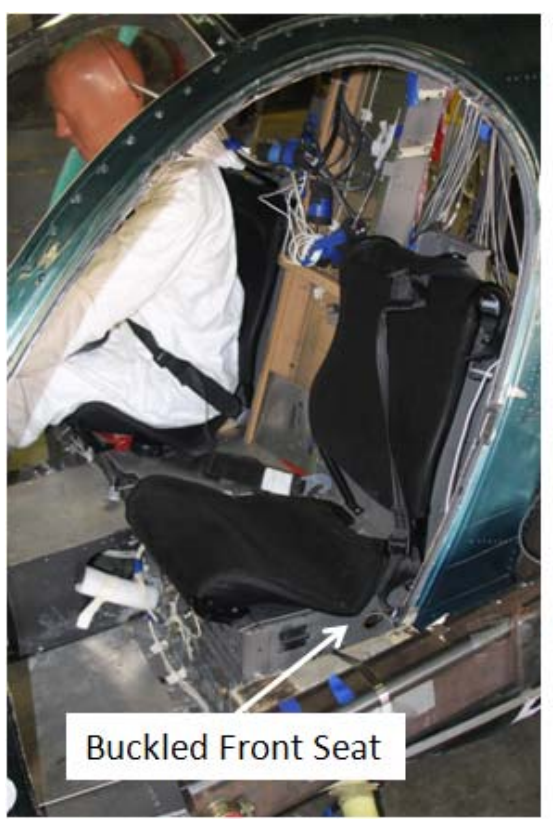

(a) - Front Seat

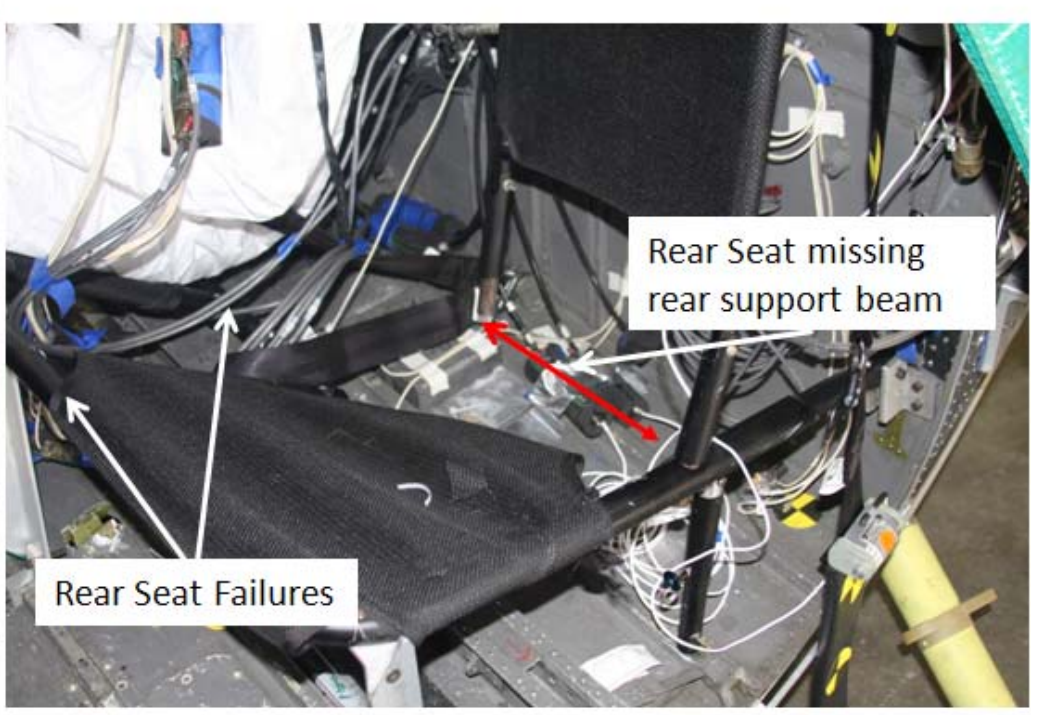

(b) - Back Seat

Fig. 9 Seat failures in MD-500 baseline test 


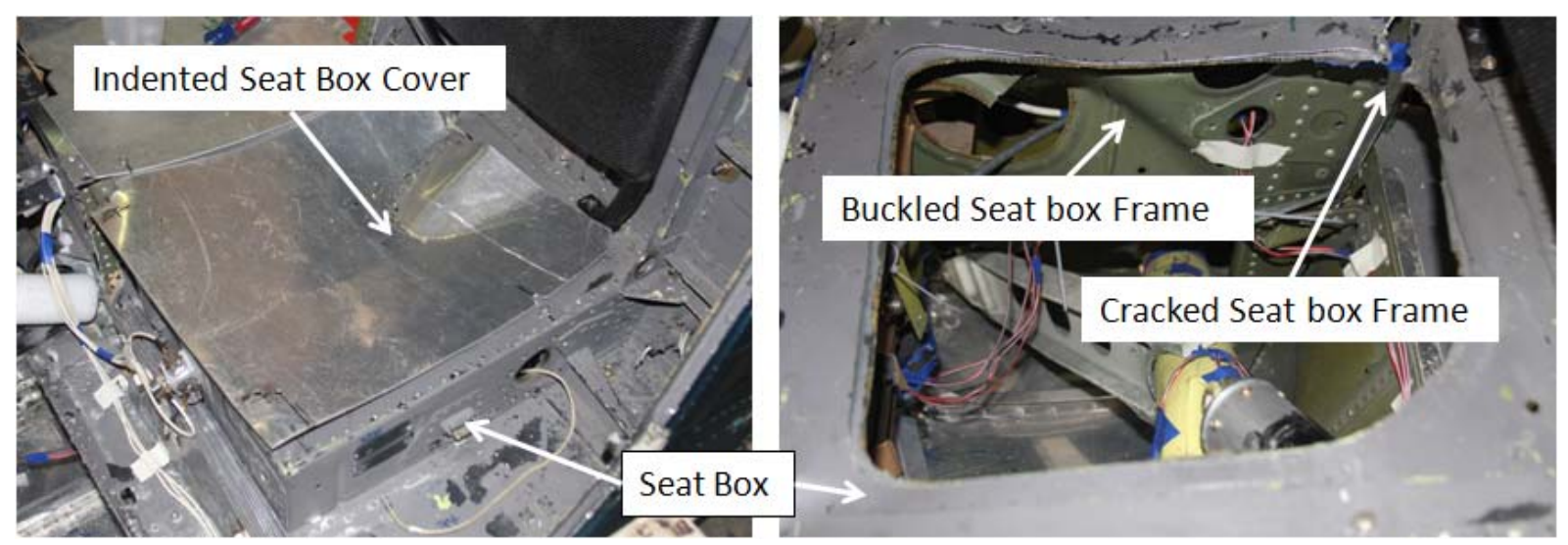

Fig. 10 Front seat box structural deformations
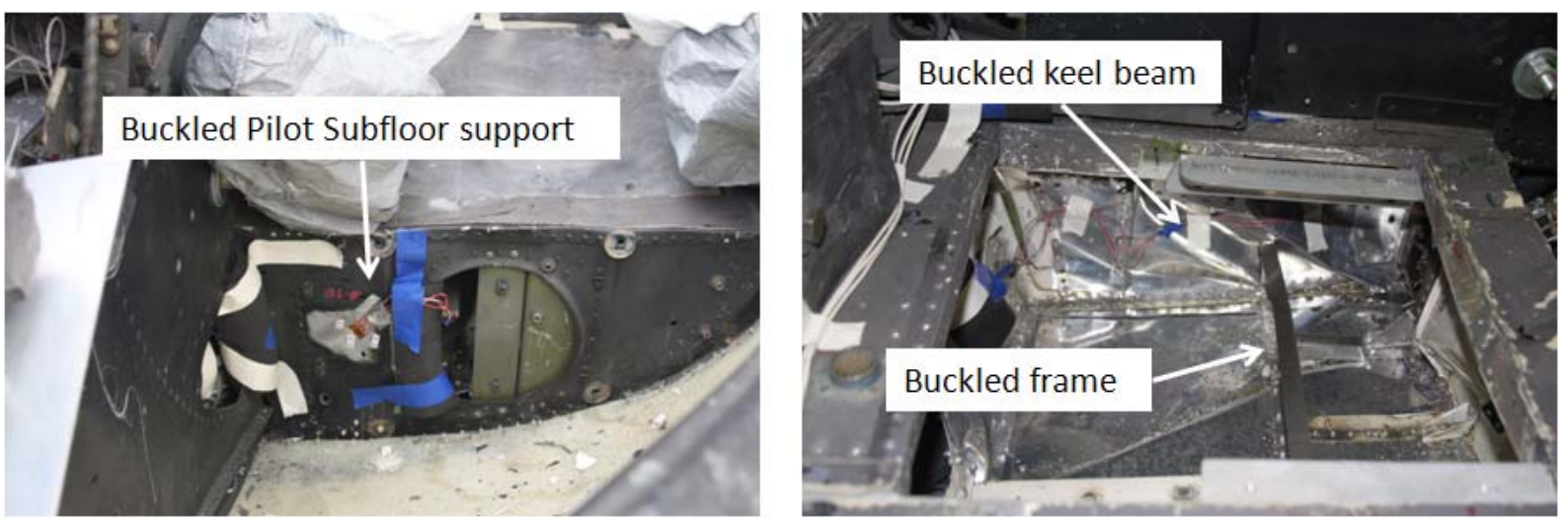

Fig. 11 Forward structural failures in MD-500 baseline test

Areas below the seat box under the pilot and copilot showed extensive buckling. The subfloor support showed signs of damage, while the middle keel beam and co-pilot frame also buckled. Figure 12 shows the damage from the keel beam under the rear occupants for the baseline test. As Figure 12 shows, major structural damage is seen in the rear keel beam. Cracks and buckled regions (not shown) were present under the rear floor, indicating major damage to the bottom section of the airframe. These failures are in contrast to the test which included the DEA, where the airframe did not show any signs of damage.

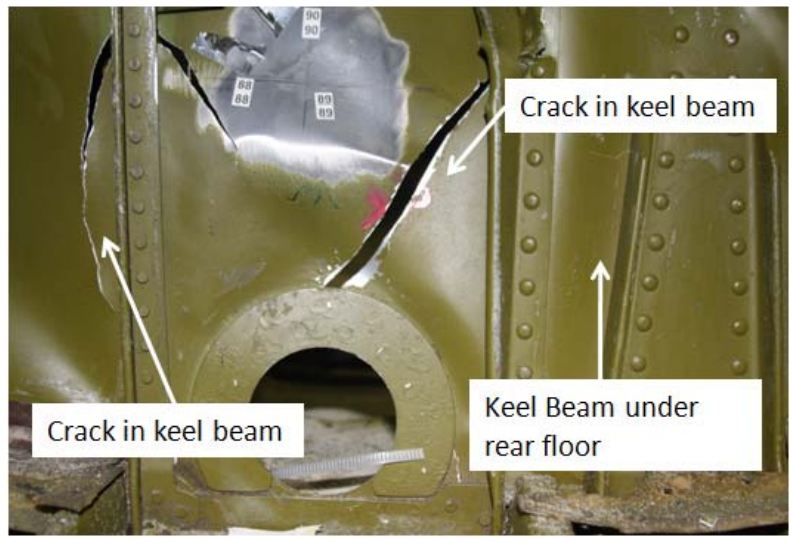

Fig. 12 Rear Keel Beam failure in MD-500 without DEA test 
Impact loads and accelerations which caused the major damage were next examined. Figure 13 shows the front floor vertical ( $z$ ) accelerations for both the left and right sides. Figure 14 shows vertical accelerations from the rear of the cabin, both on the floor and on the rear bulkhead. In both Figures 13 and 14, all accelerations were filtered with a four-pole, lowpass Butterworth filter with a $60 \mathrm{~Hz}$ cutoff frequency.

The left front floor acceleration peaks at approximately $45 \mathrm{~g}$ on the left and $55 \mathrm{~g}$ on the right for the baseline test, and approximately $15 \mathrm{~g}$ for both the left and right for the test which did include the DEA. For the baseline test, the front right floor experienced the highest acceleration levels of the entire airframe. This was due to the downward pitch and high yaw in the test, in which the front right portion of the helicopter impacted the surface first. Next, Figure 14 shows vertical (z) accelerations from locations on the rear floor and on the rear bulkhead of the helicopter.

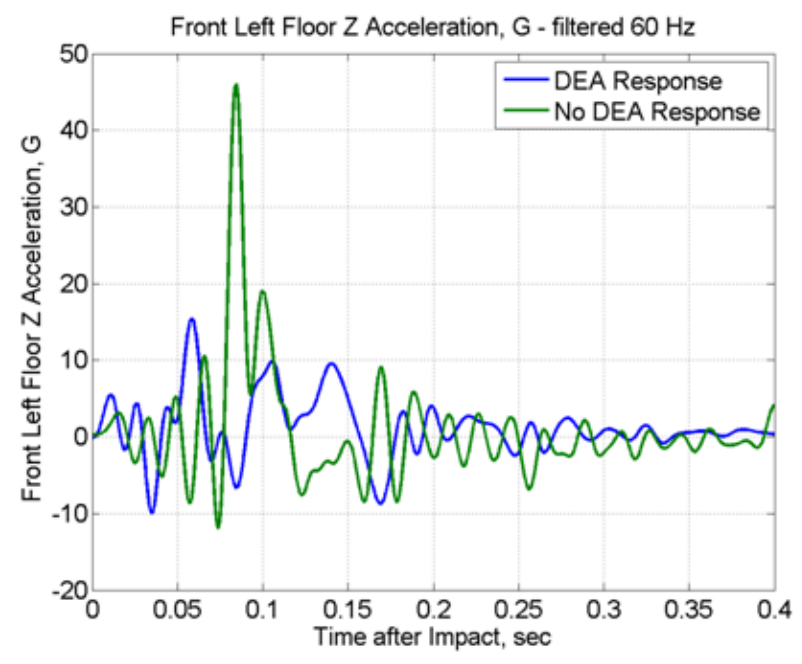

(a) - Front Left Floor Accelerations

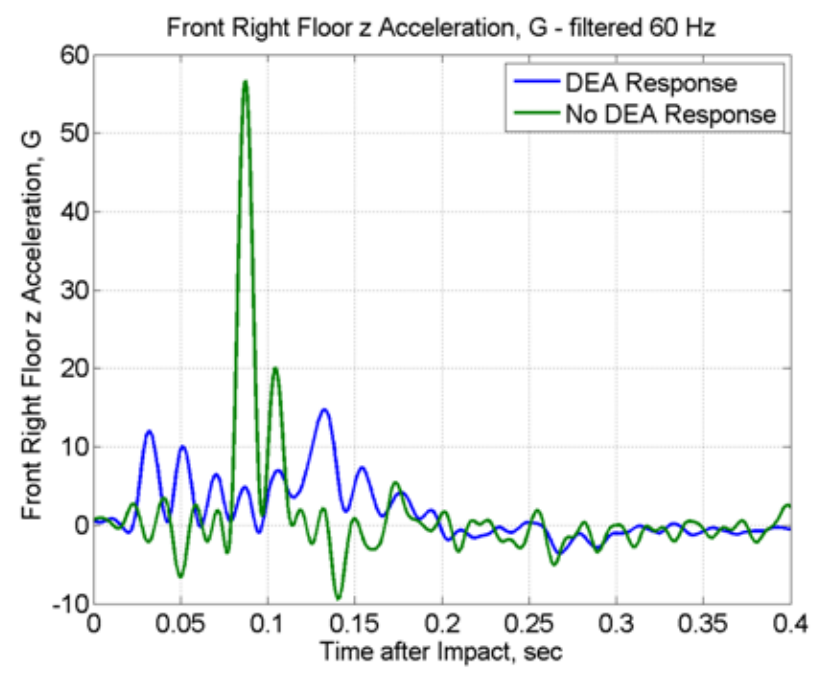

(b) - Front Right Floor Accelerations

Fig. 13 Front floor accelerations

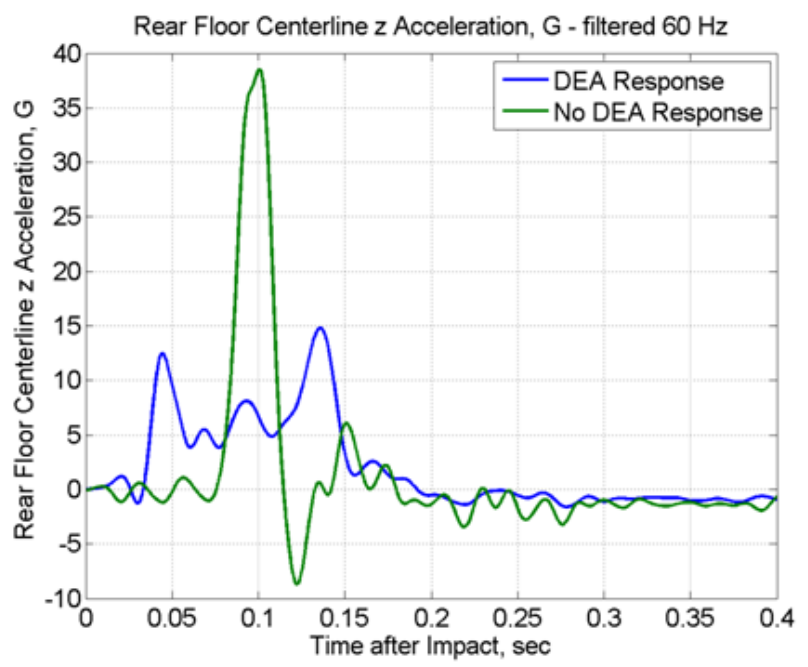

(a) - Rear Centerline Floor Accelerations

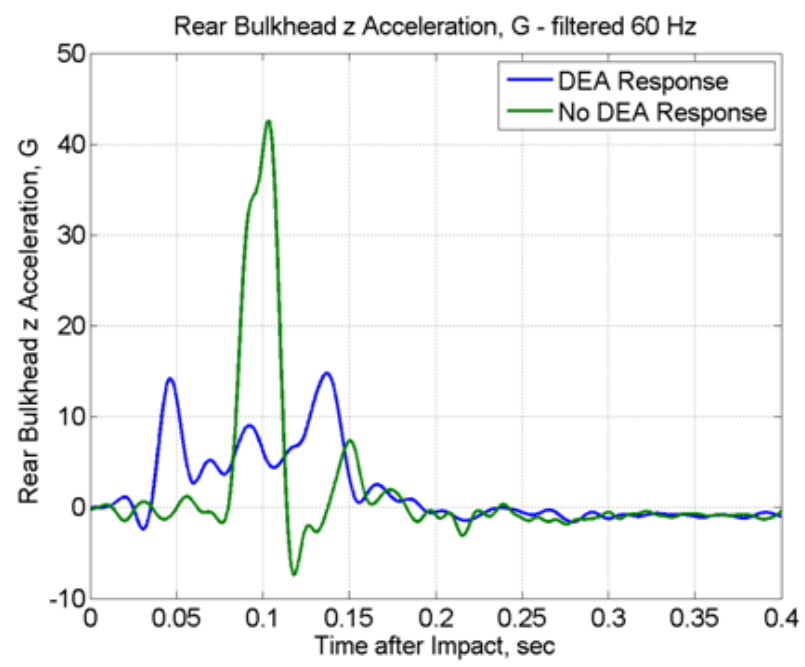

(b) - Rear Bulkhead Accelerations

Fig. 14 Rear floor and bulkhead accelerations 
The rear floor experienced a peak acceleration of approximately $40 \mathrm{~g}$, while the rear bulkhead experienced approximately $42 \mathrm{~g}$ for the baseline test. The accelerations which did include the DEA showed peaks of approximately $15 \mathrm{~g}$. One major difference between the two tests is the time history of the accelerations. The baseline test shows a large spike at approximately 0.1 seconds after impact, lasting approximately $40 \mathrm{~ms}$. The test which included the DEA showed two peaks of less magnitude at either end of a longer pulse. The peak value at the beginning of the pulse is from the initial contact between the DEA and impact surface and the peak value at the end of the pulse is from bottoming out of the DEA. The length of the pulse was approximately $120 \mathrm{~ms}$. The DEA effectively changed the shape of the impact pulse from a high magnitude, low duration pulse to a low magnitude, high duration pulse. This shape change is important when examining occupant injury. For occupant injury protection, since both the magnitude and the duration of the input pulse have an effect on occupant response [15], acceleration traces from the onboard occupants were examined next.

Three of the four onboard occupants had instrumentation recording translational accelerations in three dimensions for the head, chest and pelvis, along with lumbar load values in the spine. Figure 15 shows the head accelerations from both tests for the pilot. The baseline test is shown in Figure 15(a), while the test which included the DEA is shown in Figure 15(b).

The results in Figure 15 show that the DEA attenuated the vertical ( $z$ ) accelerations of the pilot's head from approximately $30 \mathrm{~g}$ to approximately $10 \mathrm{~g}$, or by a factor of 3 . The test which included the DEA also showed lower horizontal (x) accelerations as well, with magnitude attenuation of a factor of 2 . The test which included the DEA, however, did show higher lateral $(\mathrm{y})$ accelerations, presumably from the large amount of airframe yaw present in the impact conditions described previously. This lateral acceleration had effectively been removed for the baseline test. The data corresponds well with the photogrammetric impact condition data. Figure 16 shows the chest acceleration responses of the pilot for both tests. The baseline test is shown in Figure 16(a), while the test which included the DEA is shown in Figure 16(b).
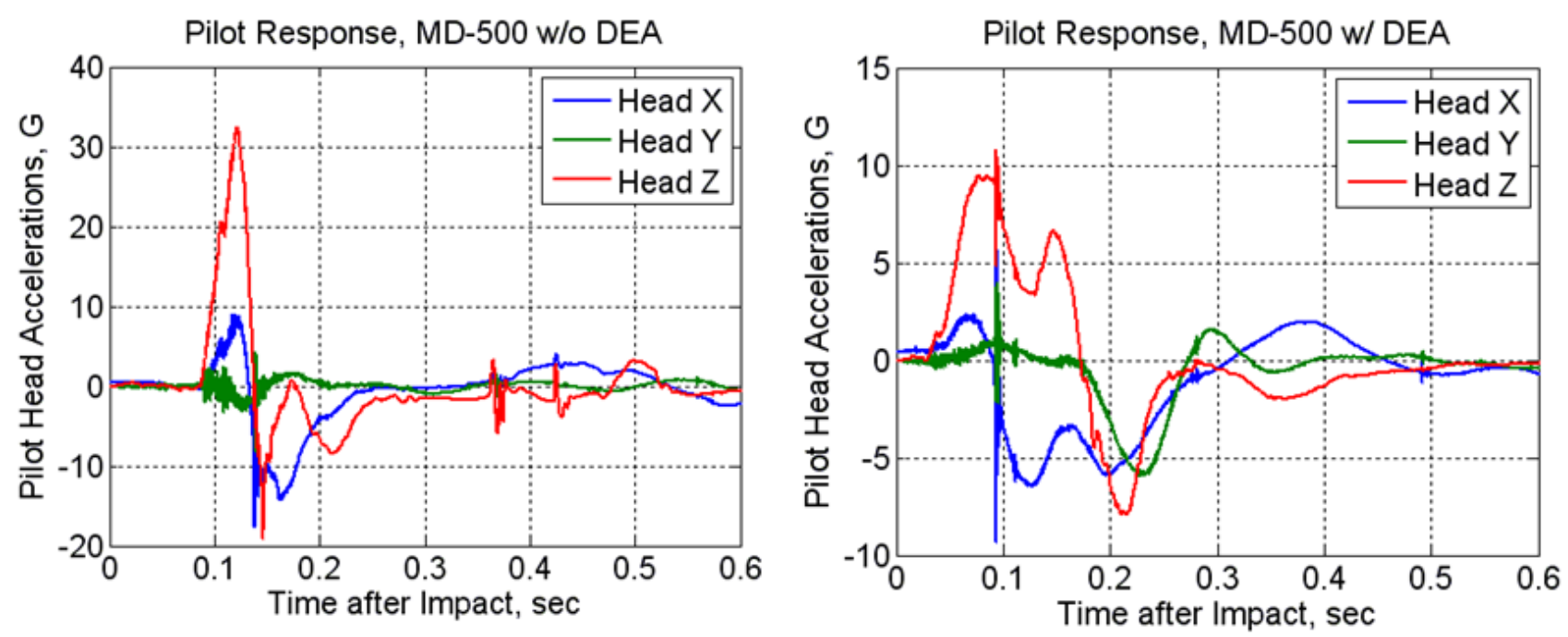

(a) - Pilot Head Response, baseline (b) - Pilot Head Response, with DEA

Fig. 15 Head Accelerations for the pilot 
Pilot Response, MD-500 w/o DEA

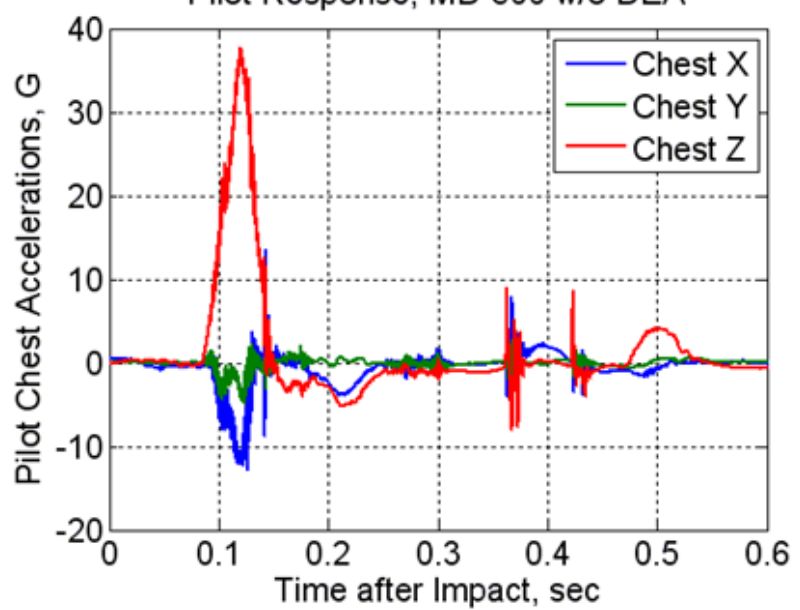

Pilot Response, MD-500 w/ DEA

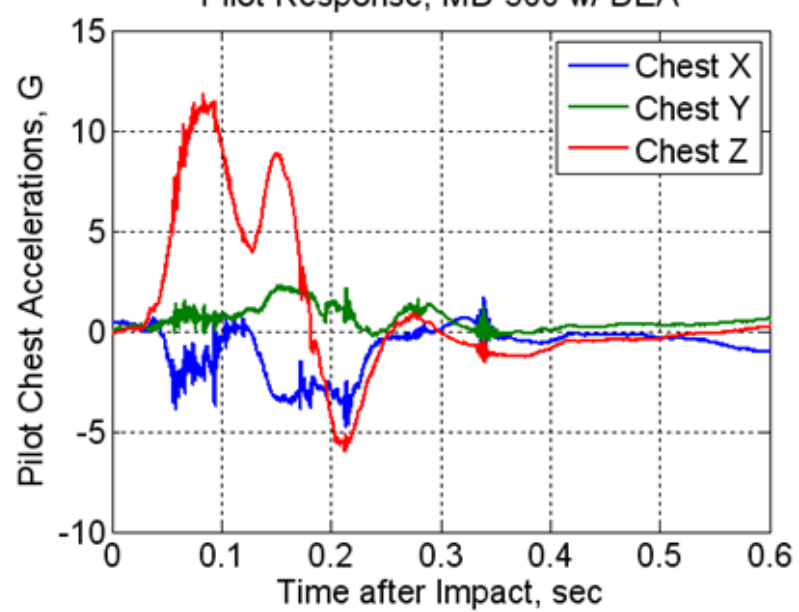

(a) - Pilot Chest Response, baseline(b) - Pilot Chest Response, with DEA

Fig. 16 Chest Accelerations for the pilot

The results in Figure 16 show that the DEA attenuated the vertical (z) accelerations for the pilot's chest from approximately $35 \mathrm{~g}$ to approximately $12 \mathrm{~g}$, or by a factor of 3 , which is similar to the results seen for the pilot's head. As with the head results, the test which included the DEA also showed lower horizontal $(x)$ accelerations, but higher lateral (y) accelerations. This finding is attributed to to the large amount of yaw present in the impact conditions for the test which included the DEA. Next, Figure 17 shows the acceleration responses from the pelvis of the pilot. The baseline test is shown in Figure 17(a), while the test which included the DEA is shown in Figure 17(b).

Pelvis accelerations matched trends seen for the occupant's head and chest. The pilot's pelvis experienced vertical $(z)$ accelerations of approximately $40 \mathrm{~g}$ for the baseline test, while experiencing only $10 \mathrm{~g}$ in the test which did include the DEA. The test which included the DEA also attenuated the pilot's horizontal accelerations by a factor of two. The head, chest and pelvic results all show an attenuation of between 2 and 4 for vertical accelerations and approximately 2 for horizontal accelerations for the occupant representing the pilot of the helicopter. The other occupant acceleration time history results showed similar trends with similar magnitudes and, for brevity, are not shown. However, the occupant lumbar load values for all three occupants containing a lumbar load cell were examined. Lumbar load responses are reported in Figure 18.

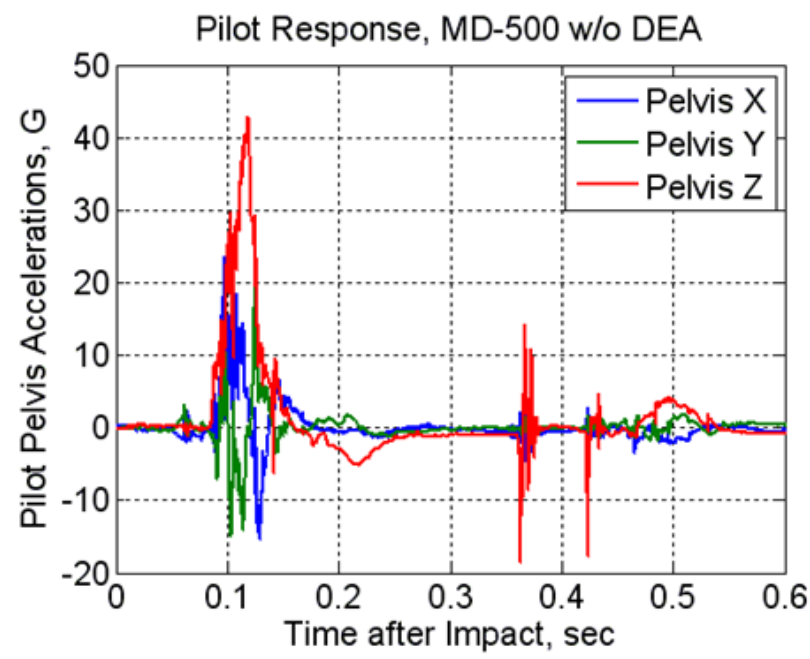

(a) - Pilot Pelvic Response, baseline

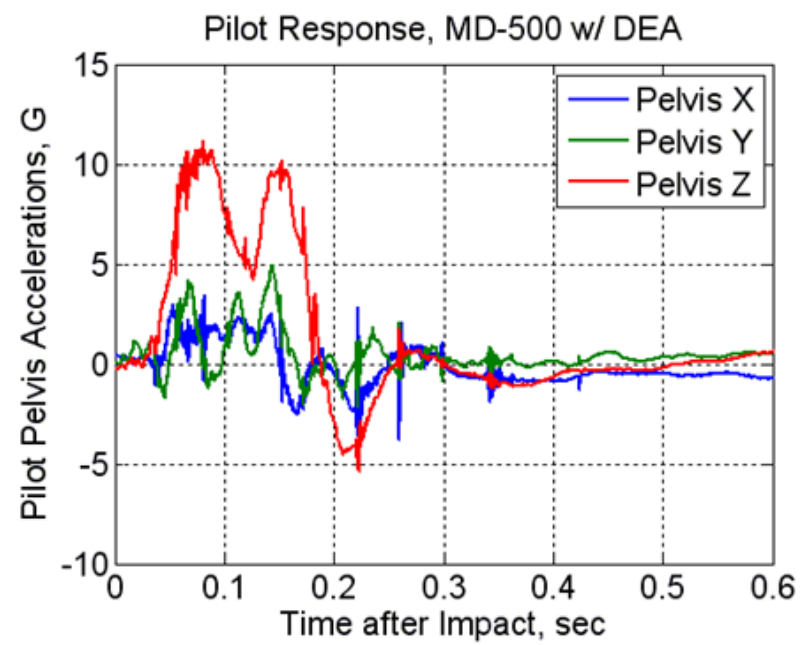

(b) - Pilot Pelvic Response, with DEA

Fig. 17 Pelvic accelerations for the pilot 


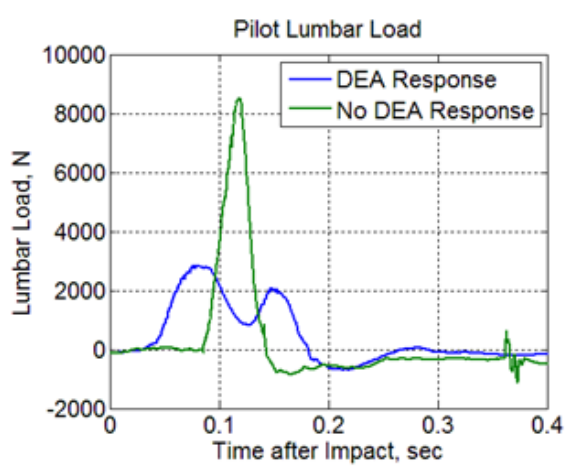

(a) - Pilot

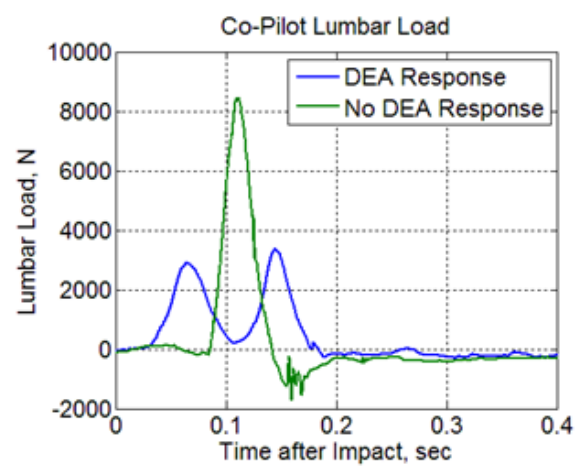

(b) - Co-pilot

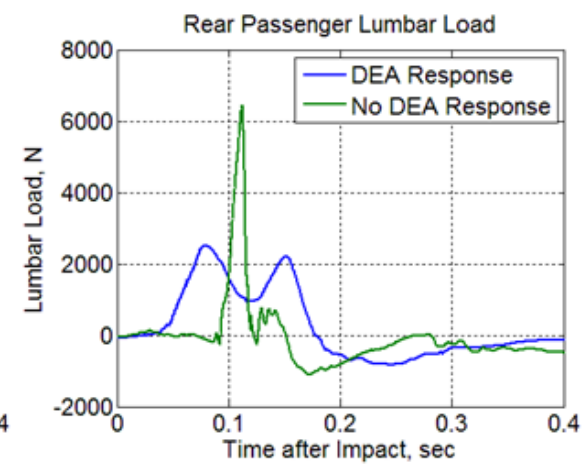

(c) - Rear Passenger

Fig. 18 Lumbar loads

The pilot and co-pilot's compressive lumbar loads reached similar magnitudes and durations for each test, presumably because they were seated in similar mesh bucket seats. The rear passenger's time history is slightly different due to its position on a bench seat. Comparing results between tests, the compressive lumbar load values were approximately 3860 , 3372 , and $2518 \mathrm{~N}(643,758$, and $566 \mathrm{lb})$ for the pilot, co-pilot and rear passenger, respectively, during the test which included the DEA; and 8536, 8461, and $6445 \mathrm{~N}(1919,1902$, and $1449 \mathrm{lb})$ for the pilot, co-pilot and rear passenger respectively for the test which did not include the DEA. The data was filtered using SAE CFC 600 with accordance to SAE J211 [16]. When evaluating potential for injury, FAR Part 27.562 (c) [17] establishes a lumbar limit of 6,672 N $(1,500 \mathrm{lb})$ as being injurious. The loads incurred in the occupants were well below this limit for the test which included the DEA, but were over the limit for the front occupants for the test which did not include the DEA. This result indicated that, when examining the lumbar load data, the DEA protected the occupant sufficiently enough to avoid injury.

The pilot, co-pilot and rear passenger seat pan accelerations were input into the Brinkley model [18], which is used to evaluate the risk of injury in a variety of aircraft and spacecraft systems [19-20]. The Brinkley model estimates the likelihood of injury using a spring/mass/damper lumped parameter representation of the body for each axis ( $x$ - chest to back direction, $y$ - sideways direction, and $z$ - vertical or spinal direction) of the occupant. The coefficients of these lumped parameters in the mathematical formulation are based on experiments conducted on volunteers from the U.S. Army and Navy.

Seat pan acceleration time history pulses in all three directions were input into the Brinkley model. The output result from the Brinkley model is the beta value, which is an index taking into account responses from all three axes. The value of beta is given for three risk categories (low, medium and high), and a beta value greater than one in a particular category pushes the injury probably into the next higher category. Table 2 lists the beta values for all occupants for both tests, with careful attention being paid to the values in italic.

The Brinkley responses show a high probability of injury for the pilot and copilot and show a medium probability of injury for the rear passenger for the baseline test. The Brinkley values confirm the results previously obtained for the lumbar loads: Both the pilot and co-pilot had a high probability of injury while the rear passenger was only slightly under high probability of injury, and very close to the limit for lumbar load and 0.01 over the limit for medium injury in the Brinkley results. For the test with the DEA, all injury probabilities were low.

Table 2 - Beta values from Brinkley Model

\begin{tabular}{|l|l|l|l|l|l|l|}
\hline Position & \multicolumn{2}{|c|}{ Beta Low } & \multicolumn{2}{c|}{ Beta Med } & \multicolumn{2}{c|}{ Beta High } \\
\hline & w/o DEA & \multicolumn{1}{|c|}{ DEA } & w/o DEA & DEA & w/o DEA & DEA \\
\hline Pilot & 1.87 & 0.70 & 1.56 & 0.59 & 1.22 & 0.46 \\
\hline Co-Pilot & 1.78 & 0.62 & 1.49 & 0.52 & 1.17 & 0.41 \\
\hline Rear Passenger & 1.24 & 0.86 & 1.01 & 0.72 & 0.81 & 0.57 \\
\hline
\end{tabular}


Finally, along with providing the six degree-of-freedom impact conditions for both tests, photogrammetry was used to examine relative deflections between the target locations identified on the helicopter. Areas of large relative deflection on the aircraft suggested possible compromises in structural integrity and damage. Figure 19 shows visually the locations chosen for the examination of relative deflections between targets while Table 3 shows the results obtained from both tests.

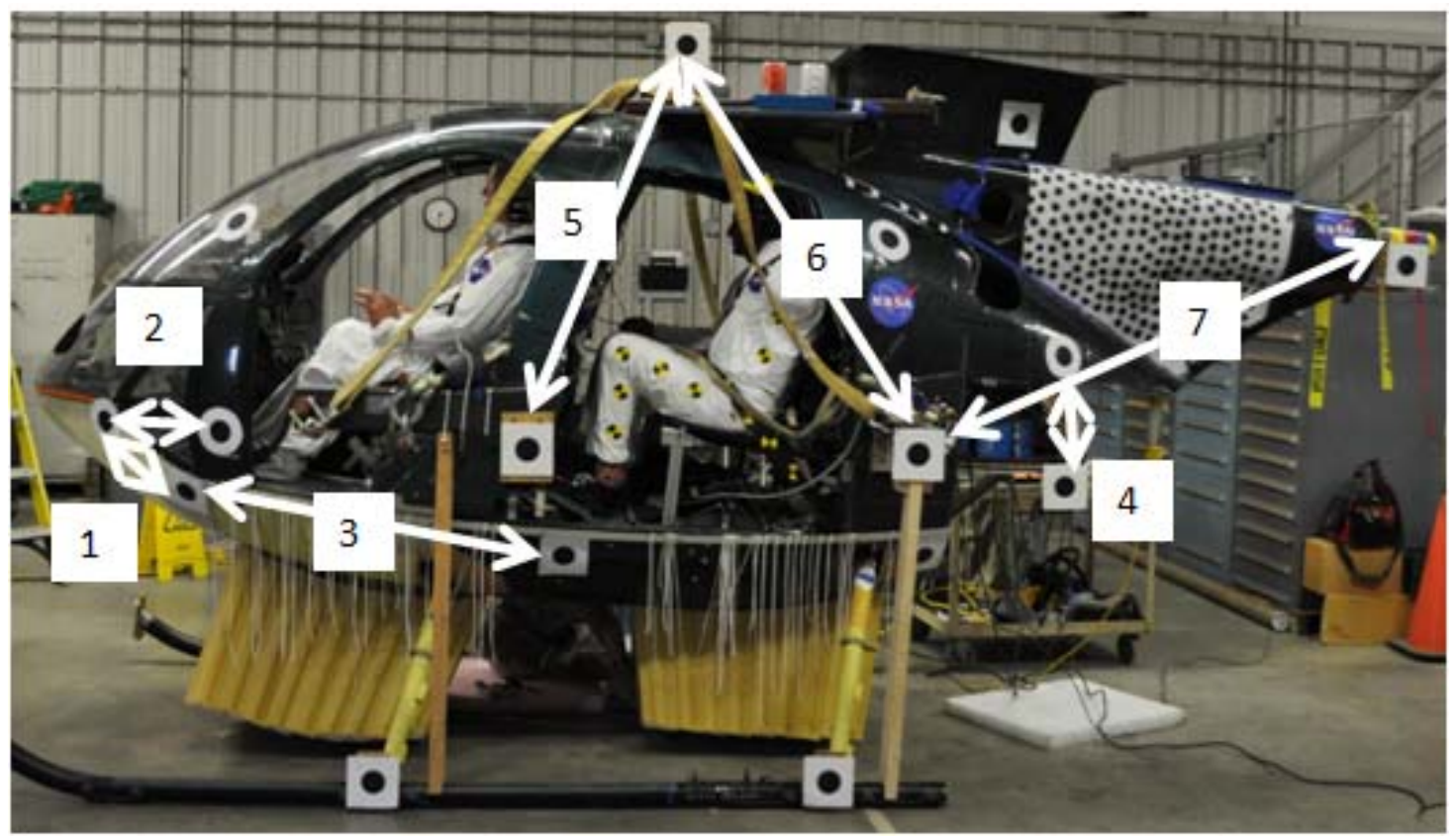

Fig. 19 MD-500 Photogrammetric Structural Deformation Locations

Table 3 - Deformations from both MD-500 helicopter tests

\begin{tabular}{|l|l|l|}
\hline Vehicle Position (ID \# - Figure 19) & $\begin{array}{l}\text { MD-500 without DEA } \\
\text { (Relative deformation, } \\
\text { \%) }\end{array}$ & $\begin{array}{l}\text { MD-500 with DEA } \\
\text { (Relative deformation, \%) }\end{array}$ \\
\hline Nose to Water Line (1) & 0.28 & 0.85 \\
\hline Seat Line (2) & 0.43 & 0.47 \\
\hline Water Line (3) & 0.16 & 0.17 \\
\hline DAS Shelf Support (4) & 2.78 & 0.98 \\
\hline Top Mass to Front Lifting fixture (5) & 0.77 & 0.32 \\
\hline Top Mass to Rear Lifting fixture (6) & 0.69 & 0.34 \\
\hline Tail to Rear Lifting fixture (7) & 1.65 & 0.24 \\
\hline
\end{tabular}

Table 3 shows that the highest relative displacements occurred in the front of the vehicle and near the rear at Position 4 , for the test which included the DEA. The relative displacements in the front occurred when the nose impacted the surface first due to the pitched down orientation of the helicopter at impact. The large deformations from the DEA crushing upon impact pushed the front targets upward while the ballast mass in the nose continued downward. However, the photogrammetry results also showed that no permanent deflection occurred. The other area of high relative deflection was near the rear of the helicopter, under the tail support, in position 4 . Position 4 measured the relative deflection on a 
bar which connected the aircraft frame to a metal plate which held the onboard data acquisition system, acting as the ballast mass for the engine. The plate and data acquisition system weighed approximately $69 \mathrm{~kg}(150 \mathrm{lb})$ total, and was attached to brackets located on the tail. During impact, the inertial load into the tail due to the large amount of ballast mass in combination with the large amount of compliance in the tail caused the surrounding airframe to deform. However, the deformation was elastic in nature and the structure rebounded to its pre-impact position. All other areas examined exhibited low deflection, and confirmed the findings from the visual inspections that the airframe was relatively undamaged.

Large relative deformations were seen for the test which did not include the DEA, and confirmed the findings seen in Figures 8 through 12. The common trend in the photogrammetry data showed that the areas which had large amounts of ballast mass produced the areas of largest displacement. Ballast mass for the main rotor affected both Position 5 and 6 , ballast mass for the engine affected position 4 and ballast mass for the tail rotor affected position 7 . These inertial loads were not absorbed by the DEA structure since it was not included in the second crash test, which deformed the airframe the greatest amount. These photogrammetric results, along with acceleration profiles and visual inspections post-test showed that the airframe was unusable after the test.

\section{Summary}

Two full scale crash tests were conducted on an MD-500 helicopter airframe to examine, in part, the performance of a deployable energy absorbing (DEA) concept. In the first test, the DEA was attached to the bottom of an instrumented MD500 helicopter, which impacted a concrete surface at a resultant velocity of $14.2 \mathrm{~m} / \mathrm{s}(46.5 \mathrm{ft} / \mathrm{s})$. The response data shows that the airframe experienced a peak acceleration of approximately $15 \mathrm{~g}$ in the vertical and $8 \mathrm{~g}$ in the horizontal directions. Airframe deflection data from photogrammetry measurements suggested that the airframe survived the impact relatively undamaged after the impact. The occupant data was processed through various injury criteria's, all of which showed no injury.

These results are in contrast to a second test which was conducted as a baseline to evaluate the DEA performance. The test which did not include the DEA showed vertical airframe accelerations of approximately $40 \mathrm{~g}$. The various injury criteria showed a medium to high risk of injury for the onboard occupants. The test program demonstrated that the DEA can be a valuable energy absorbing or attenuation mechanism for aircraft, and can be modified to applications for future aircraft or spacecraft.

\section{References}

[1] O'Bryan, Thomas C., and Hewes, Donald E., "Operational Features of the Langley Lunar Landing Research Facility," NASA Technical Note, TN D-3828, February 1967.

[2] Vaughan, Jr., Victor L. and Alfaro-Bou, Emilio, "Impact Dynamics Research Facility for Full-Scale Aircraft Crash Testing," NASA Technical Note, TN D-8179, April 1976.

[3] Jackson, K.E., et al, "A History of Full-Scale Aircraft and Rotorcraft Crash Testing and Simulation at NASA Langley Research Center," NASA TM 20040191337, 2004.

[4] Shane, J.S., "Design and Testing of an Energy-Absorbing Crewseat for the F/FB-111 Aircraft," NASA CR-3916, August 1985.

[5] Tutt, B., et al, "A Summary of the Development of a Nominal Land Landing Airbag Impact Attenuation System for the Orion Crew Module," 20th AIAA Aerodynamic Decelerator Systems Technology Conference, Seattle, WA, 4-7 May 2009.

[6] Kellas, S., "Deployable Rigid System for Crash Energy Management," US Patents 6,755,453, June 29, 2004; 6,976,729, December 20, 2005; and 7,040,658, May 92006. 
[7] Kellas, S. and Jackson, K. E., "Deployable System for Crash-Load Attenuation," Proceedings of the 63rd AHS Annual Forum, Virginia Beach, VA, May 1-3, 2007.

[8] Kellas, S. and Jackson, K.E., "Multi-Terrain Vertical Drop Tests of A Composite Fuselage Section," Proceedings of the $64^{\text {th }}$ Annual AHS Forum, Montreal, Canada, April 29-May 1, 2008.

[9] Kellas, S., et al, "Full Scale Crash Test of an MD-500 Helicopter with Deployable Energy Absorbers," Proceedings of the $66^{\text {th }}$ AHS Annual Forum, Phoenix, AZ, May 11-13, 2010.

[10] MD Helicopters. MD-500E Rotorcraft Flight Manual Revision 14. CSP-E-1. 1982.

[11] Gowdy, V. et al, "A Lumbar Spine Modification to the Hybrid III ATD for Aircraft Seat Tests", SAE 1999-01-1609. 1999.

[12] Roberts, J., et al, "Computational and Experimental Models of the Human Torso for Non-Penetrating Ballistic Impact", Journal of Biomechanics, Vol. 40, pp. 125-136, 2007

[13] Military Standard, MIL-STD-1290A (AV), Light Fixed- and Rotary-Wing Aircraft Crash Resistance, Department of Defense, Washington DC, 20301, 26 September 1988.

[14] Littell, J.D. "Large Field Photogrammetry Techniques in Aircraft and Spacecraft Impact Testing," Proceedings from the Society of Experimental Mechanics Annual Conference, Indianapolis, IN, June 7-10, 2010.

[15] Eiband, A.M., "Human Tolerance to Rapidly Applied Accelerations: A Summary of the Literature," NASA Memorandum 5-19-59E, June 1959.

[16] Society of Automotive Engineers (SAE). "Recommended Practice: Instrumentation for Impact Test - Part 1, Electronic Instrumentation," SAE J211/1, March 1995.

[17] Code of Federal Regulations. Federal Aviation Regulations for Aviation Maintenance Technicians FAR AMT, Part 27 Airworthiness Standard: Normal Category Rotorcraft, 27.562 Emergency Landing Dynamics.

[18] Brinkley, J.W., Specker, L.J., and Mosher, S.E., "Development of Acceleration Exposure Limits for Advanced Escape Systems," NATO AGARD Proceedings, AGARD-CP-472, February 1990.

[19] Jackson, K.E., et al, "Occupant Responses in a Full-Scale Crash Test of the Sikorsky ACAP Helicopter," Journal of the American Helicopter Society, Vol 49, No. 2, April 2004.

[20] Lawrence, C., et al, "The Use of Vehicle Acceleration Exposure Limit Model and a Finite Element Crash Test Dummy Model to Evaluate the Risk of Injuries During Orion Crew Module Landings," NASA TM 2008-215198, 2008. 